\title{
Erratum to: Long-Term Quantification of Stream-Aquifer Exchange in a Variably-Saturated Heterogeneous Environment
}

\author{
V. Phogat ${ }^{1}$ • N. J. Potter ${ }^{2}$ • J. W. Cox ${ }^{1,3} \cdot$ J. Šimůnek ${ }^{4}$
}

Published online: 2 October 2017

(C) Springer Science+Business Media B.V. 2017

\section{Erratum to: Water Resour Manage \\ https://doi.org/10.1007/s11269-017-1752-0}

The original version of this article unfortunately missing the last page of the reference list. These are the missing references:

Taylor AR, Lamontagne S, Crosbie R (2013) Measurements of riverbed hydraulic conductivity in a semi-arid lowland river system (Murray-Darling Basin, Australia). Soil Res 51:363-371.

Thompson S (2003) Using Hydrus 2D to model tree belts for salinity and recharge control. Submitted in partial fulfilment of the requirements of the Degree of Bachelor of Engineering (Environmental) with Honours. Centre for Water Research, The University of Western Australia, Perth.

Xian Y, JinM, Liu Y, Si A (2017) Impact of lateral flow on the transition from connected to disconnected stream-aquifer systems. J Hydrol 548:353-367.

The original article was corrected.

The online version of the original article can be found at https://oi.org/10.1007/s11269-017-1752-0

\section{Phogat}

vinphogat@gmail.com

1 South Australian Research and Development Institute, GPO Box 397, Adelaide, SA 5001, Australia

2 CSIRO Land \& Water Flagship, GPO Box 1666, Canberra, ACT 2601, Australia

3 The University of Adelaide, PMB1, Glen Osmond, SA 5064, Australia

4 Department of Environmental Sciences, University of California, Riverside, CA 92521, USA 